\title{
A Concise Review of Control Techniques for Reliable and Efficient Control of Induction Motor
}

\author{
Alwadie. A \\ Departement of Electrical Engineering, Faculty of Engineering, Najran University, Saudi Arabia
}

\begin{tabular}{l}
\hline \hline Article Info \\
\hline Article history: \\
Received Feb 15, 2018 \\
Revised Apr 10, 2018 \\
Accepted Jul 1, 2018 \\
\hline Keyword: \\
Optimization \\
Scalar control \\
Sensor-less control \\
Variable frequency drive \\
Vector control
\end{tabular}

\begin{abstract}
Induction motors are work-horse of the industry and major element in energy conversion. The replacement of the existing non-adjustable speed drives with the modern variable frequency drives would save considerable amount of electricity. A proper control scheme for variable frequency drives can enhance the efficiency and performance of the drive. This paper attempt to provide a rigorous review of various control schemes for the induction motor control and provides critical analysis and guidelines for the future research work. A detailed study of sensor based control schemes and sensor-less control schemes has been investigated. The operation, advantages, and limitations of the various control schemes are highlighted and different types of optimization techniques have been suggested to overcome the limitations of control techniques.
\end{abstract}

Copyright () 2018 Institute of Advanced Engineering and Science. All rights reserved.

\section{Corresponding Author:}

Alwadie. A,

Departement of Electrical Engineering,

Faculty of Engineering, Najran University, Saudi Arabia.

Email: asalwadie@nu.edu.sa

\section{INTRODUCTION}

The induction motors are mainly used for adjustable speed applications and consume approximately $60 \%$ of the total energy of the plant [1]. Before the invention of semiconductor devices like silicon controlled rectifier, direct current (DC) motors were used in the industry. Although, DC motors were capable to deal with high torque applications, but they need high cost for maintenance. Thus, DC motors were largely replaced with alternating current (AC) motors and now a days, AC motors are being used in off-shore pumping stations, cranes, blowers, textile industry and refineries. The usage of induction motors on large scale is due to the fact that their maintenance is easy and have high efficiency. The commercial usage of adjustable speed drives was started in 1960 and steady state speed control under low dynamics based on voltage frequency ratio (v/f) of the induction motor was major focus of the research. Later on, slip frequency control method become famous for improved dynamics of the motor. With the time, researchers developed more efficient methods like field oriented control of speed of induction motor[2].

The techniques used to control speed and torque of the induction motor are classified as scalar and vector control techniques [3-8]. The scalar control technique has several advantages like, parameter independent modelling, stability in control of medium to high speed operation, easy design, simple structure, low steady-state error and low cost and hence, several research studies have utilized the scalar control method via digital signal processors $[3,4,5,7,9]$. The vector control technique has high controlling performance for induction motor speed and thus, is the most widely used control strategy [7, 10-13]. The vector control method is mainly utilized for controlling the position of the flux, current vectors and voltage. The vector control strategy has two main drawbacks 1) coupling between flux and electromagnetic torque 2) the sensitivity of the controller to induction motor parameters. These problems are resolved through direct field oriented control (DFOC) and indirect field oriented control (IFOC). DFOC and IFOC are utilized to achieve the decoupling of the flux and torque [8]. 
For the control of induction motor drives, many control techniques has been developed and used in the past. Proportional integral derivative (PID) controller is one of the conventional technique. Due to its simple design and low cost, PID controller was utilized by the researchers for regulating the speed, torque and flux in induction motors. However, the intensive calculations are required to calculate the parameters of the PID controller [8].

The fuzzy logic controller has capability to adapt according to the sudden event changes in the system and can be used for linear and non-linear systems. Fuzzy controller utilized the fuzzy theory and the design of the fuzzy controller is based on linguistic rules, which is the basis of human logic [14-19]. The fuzzy controller design has three main phases: 1) fuzzification: to converts the inputs into fuzzy sets 2) inference engine: to define the fuzzy rules which relate the outputs with the inputs and 3) defuzzification: combines the results of the fuzzy rules, and infers the decision, which is then converted from fuzzy sets to a crisp value. Several studies have used fuzzy controller to improve the control features for the scalar speed control of IMs [20-24]. Some of the researchers have used fuzzy controller to develop the vector control of the induction motor.

The sliding mode control (SMC) scheme have been the focus of researchers for many decades [25, 26]. The SMC use the discontinuous control action to drive the state trajectories of the controlled system in specified sliding hydroplane in the state space. The purpose of state trajectories is to keep sliding on specific sliding hydroplane until the origin of the state-space is reached [27]. The SMC scheme has the main advantage in improving the stability and robustness of the system [28]. However, chattering phenomenon is the main drawback of using the SMC [29]. To overcome this issue, few researchers have suggested the fuzzy sliding mode controller (FSMC). Although, the FSMC has the capability to improve the stability and robustness and can tackle the chattering effect but the key challenge in the use of FSMC is in designing the rules of the FSMC systems.

Another technique commonly used in induction motor control is Pulse width modulation (PWM) driving three-phase voltage source inverter [23, 30-33]. The voltage source inverter are used to regulate the output voltage (AC) and frequency from a supply voltage (constant DC). The key features of the PWM technique are that the output voltage has minimum harmonics, low distortion, high efficiency and low switching losses.

Several techniques and algorithms such as swarm intelligence method and evolutionary algorithms (EA) which are used for the optimization of the controller performance has been reported in the literature [3442]. The most popular swarm intelligence optimization algorithms are: 1) Particle Swarm Optimization (PSO), 2) Artificial Bee Colony (ABC), 3) Ant Colony Optimization (ACO) 4) Ant Colony Optimization. These all algorithms are based on the nature inspired computational methodologies. For example, The PSO technique has been developed based on the movements of bird grouping or fish flocking [36]. The $\mathrm{ABC}$ technique has been developed using the food-searching behavior of insects and honeybees [34]. Meanwhile, the behavior of ants for searching the optimal path between their camp and food source has been utilized in the development of ACO algorithm [35]. The working principle behind the development of EAs is natural genetic evolution, the Darwin theory and other evolutionary theories. The genetic algorithm (GA) [38], genetic programming, differential evolution, evolutionary strategy and evolutionary programming, [39] are the most commonly used EA algorithms.

The performance of the control systems has been greatly improved through the recently developed optimization techniques. In [43-45], the control of the induction motor drives has been improved through optimization techniques compromising of conventional controllers. Similarly, [17] has utilized differential search algorithm to optimize the fuzzy logic controller for photovoltaic inverters. In [46] the fuzzy logic controller was optimized using PSO technique to achieve maximum power point tracking in grid connected photovoltaic inverters. The genetic algorithm (GA) was utilized by [22, 47] for the selection of proportionalderivative-integral (PID) controller coefficients to control the speed of an induction motor. Similarly, a hybrid algorithm of PSO and GA was used to improve the performance of the optimal torque control of induction motor [48]. Kalman filter covariance technique, multi-objective fuzzy decision making [49, 50] and finitecontrol set model predictive control algorithms has been reported in [49-51] to achieve high performance of the induction motor derives control using an advanced predictive torque controller. The performance of the fuzzy logic speed controller in induction motor derives has been improved using backtracking search algorithm optimization technique [19]. Although, the optimization techniques discussed above have capability to improve performance of the control methods, however, these techniques have limitations on optima trapping, local minima, global minimum, trial-and-error procedure and long computational time to attain best optimization performances.

In this paper, various control schemes to enhance the performance and reliability of the variable frequency drives. The operational advantages and limitations of each method are highlighted for various applications of the induction motor drives. Various optimization algorithms have been suggested to overcome the limitations of the control schemes for the development of advance control system. 
Rest of the paper has been structures as follows: Section II presents review of sensor based control techniques. Section III provides review of sensor-less control schemes. Various optimization algorithms to improve the performance of the control techniques have been presented in Section IV. Section V gives the critical analysis of the literature review and finally, Section VI presents the conclusion of this paper.

\section{SENSOR BASED CONTROL TECHNIQUES}

The induction motor control mainly consist of the induction motor, load, motor drive (inverter) and control system. The interfacing of these parts and the block diagram of the complete system are shown in Figure 1 and Figure 2 respectively. Variable frequency drive control techniques for speed, torque, flux, voltage and current control are mainly classified as scalar control technique and vector control technique. The classification of VFD control schemes has been shown in Figure 3.

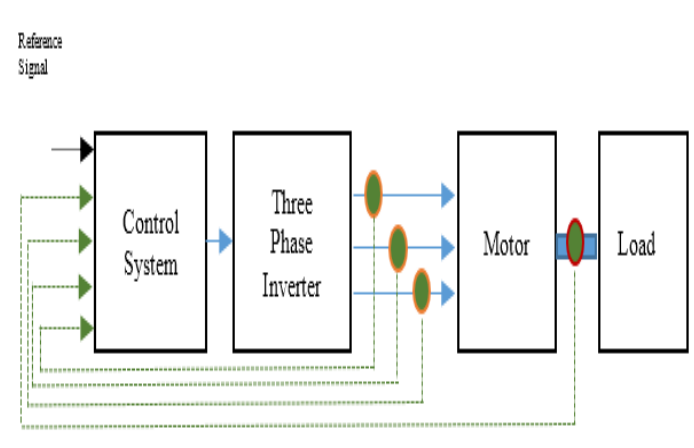

Figure 1. The Interface of the Various Parts of the Induction Motor Control System

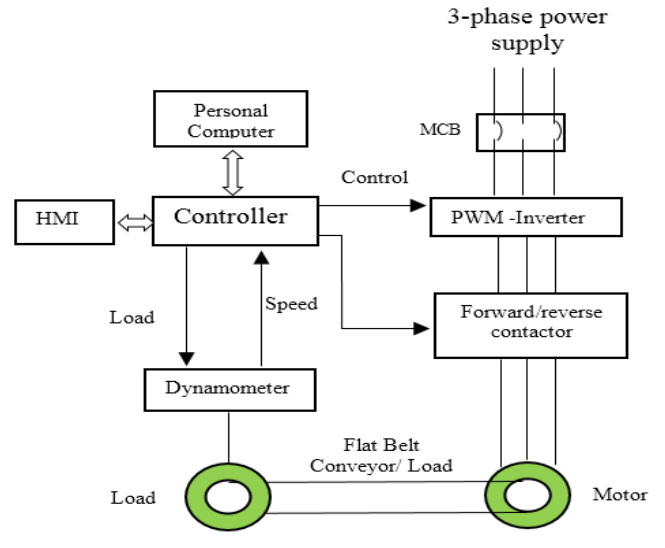

Figure 2. The Block Diagram of the Test Bench for the Induction Motor Control System

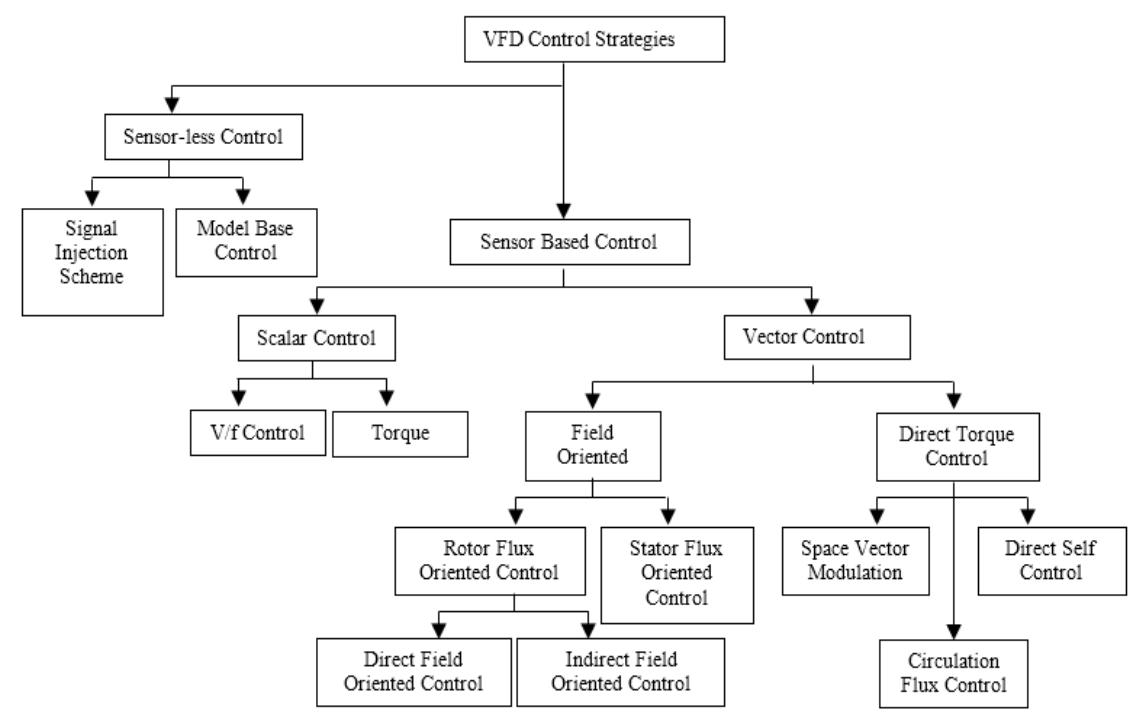

Figure 3. Classification of VFD Control Schemes

\subsection{Scalar Control Technique}

Scalar control technique utilizes the magnitude and frequency of the applied voltage to control the speed of the induction motor. In this method, a voltage source inverter is used to maintain the magnetizing current at constant value by changing the magnitude of applied voltage proportional to the applied frequency. 
This method is also known as constant volts per hertz (or constant V/f) method and its description has been shown in Figure 4. The actual speed has been measured through encoder (speed sensor) and has been utilized as a feedback. The difference of measured speed with the reference speed has been given as an error signal to the proportional-integral controller to generate the fundamental frequency reference. The amplitude of the fundamental stator voltage reference has been obtained through the fundamental stator frequency reference. Notably, if open loop control system configuration has been adopted then the speed regulation will be poor and heavily depends on the motor load. On the other hand, the close loop control system can achieve good speed response but still the system not suitable for precise torque control [52].

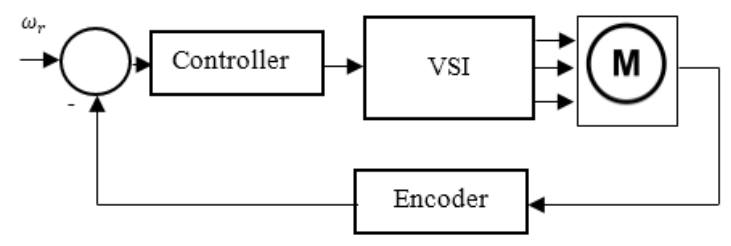

Figure 4. The Block Diagram of the Scalar Control Method

\subsection{Vector Control Technique}

Due to its high performance, the vector control technique is widely used in many induction motor control applications. The magnitude and phase of supply voltages or currents is utilized by the vector control technique to control induction motors. Due to involvement of the phase information, the vector control technique is capable of controlling the position of the flux, voltage, and current vectors of the induction motor. The Clarke and Park transformations are the mathematical tools utilized by the vector control technique for generating torque and flux, respectively. The main drawback of these transformations is the coupling between electromagnetic torque and flux. To address this issue, field oriented control (FOC) has been introduced by various researchers $[4,7,11,53]$.

\subsection{Field Oriented Control (FOC)}

FOC was proposed by the Hasse and Blaschke [54]. Many researchers have worked on the improvement of the FOC and now it has become an industrial standard control strategy. FOC control scheme is based on dynamic model of the induction motor where the fluxes, voltages and currents are represented in space vector forms. The space vector representation of the motor parameters is valid under both steady state and transient conditions and an excellent transient response can be achieved due to this feature of FOC. In the rotor flux FOC scheme, all quantities rotating at synchronous speed will appear as DC quantities. In rotating flux reference frame, if the flux is aligned to the " $\mathrm{d}$ " axis, then the " $\mathrm{d}$ " and "q" components of the stator current represent the flux and torque component respectively. Thus, in FOC control scheme, the control of induction motor looks similar to a DC motor control scheme where the torque and flux components are decoupled [55-66]. The FOC control scheme has further two types: 1) Direct field oriented control (DFOC), in which the flux position is obtained through the information of the terminal variables and rotor speed. 2) In indirect field oriented control (IFOC), in which the summation of the slip position and rotor position give the information of flux position. The block diagram of the DFOC and IFOC are shown in Figure 5 and Figure 6 respectively. The accuracy of the rotor position measurement is a key factor in rotor flux FOC scheme. Inaccurate measurement of the rotor position will result in deterioration of the torque dynamics. Alternatively, another type of FOC has been developed which is based on the stator flux orientation and thus known as stator flux FOC [67]. 


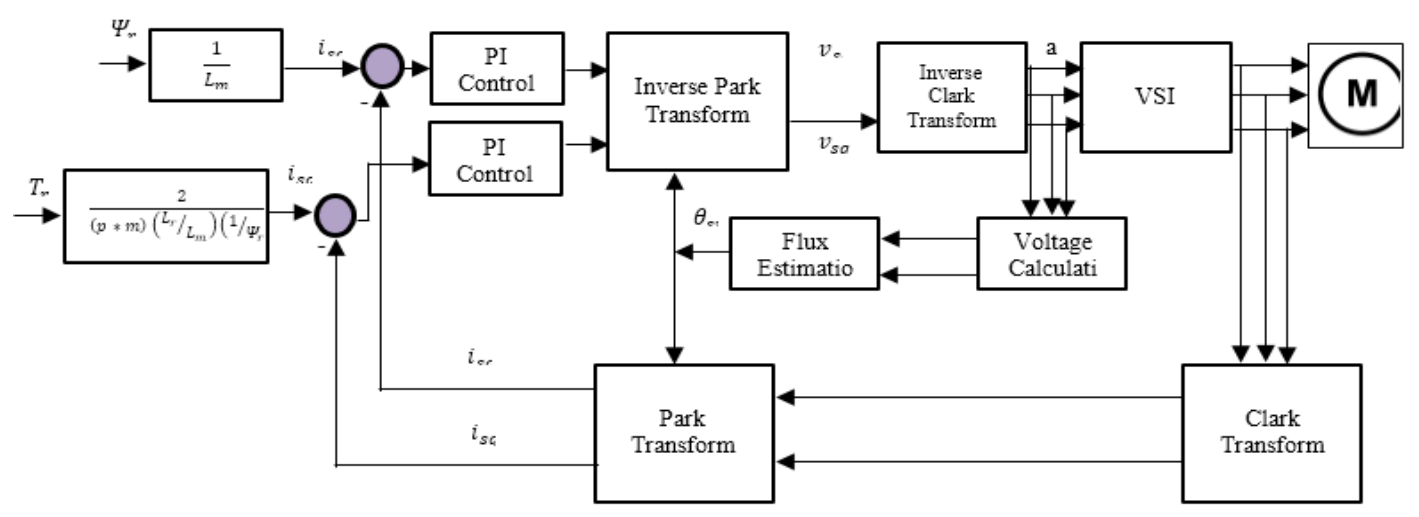

Figure 5. The Block Diagram of the DFOC Control Scheme

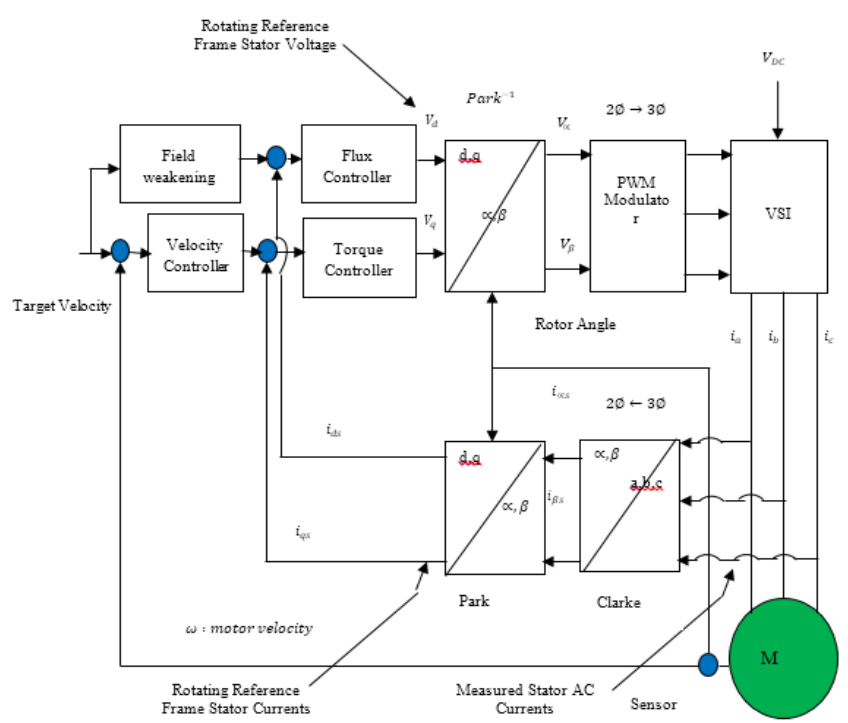

Figure 6. The Block Diagram of the IFOC Control Scheme

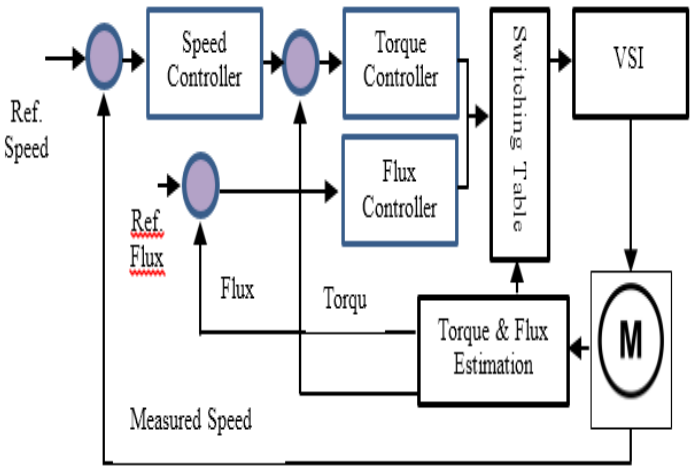

Figure 7. The Block Diagram of the DTC Control Scheme

\subsubsection{Direct Torque Control (DTC)}

Although FOC was capable to approve the response of the motor but FOC has several drawbacks in its implementation as it needs computationally complex algorithm to transform reference frame. Another shortcoming of the FOC is its dependency on the motor parameters and mechanical speed. To tackle the challenges faced by FOC, researchers have introduced, new techniques which are known as direct torque control (DTC), [68]. Recently, direct self-control (DSC), and classical DTC [68-72] have been proposed for the improvement of conventional DTC. The DTC control scheme has several advantages like high reliability, simplicity, insensitivity to the motor parameters and fast dynamic response. In DTC control scheme, the errors of the torque and stator flux status are measured and then sent to the hysteresis comparator for digitization. The location of the voltage vector has been identified through the status of the inverter switches. The status of the inverter switches is calculated using a pre-determined switching table. The main drawbacks of using DTC controller are large torque and flux ripples and the non-constant switching frequency of the inverter [72]. The block diagram of the basic DTC control scheme has been shown in Figure 7. The comparison of the scalar and vector control schemes has been summarized in Table 1 . 
Table 1. The Comparison of Scalar Control and Vector Control Schemes

\begin{tabular}{llll}
\hline \multicolumn{1}{c}{ Scalar Control } & \multicolumn{1}{c}{ Vector Control } \\
\hline 1. & Control could be performed with only one sensor (speed & 1. & $\begin{array}{l}\text { Control schemes use number of sensors to measure } \\
\text { speed, flux, torque, current, voltage etc. }\end{array}$ \\
& sensor). & 2. & Control scheme has complex structure. \\
2. & Control scheme has simple structure. & 3. & High current ripples (as in DTC) \\
3. & Low current ripples & 4. & High cost \\
4. Low cost & 5. & Control scheme is dependent on motor parameters. \\
5. Control schemes is not dependent on motor parameters. & $6 . \quad$ Control scheme requires transformation of coordinate \\
6. Control scheme does not require transformation of & & (Park Transform) \\
\hline
\end{tabular}

\section{SENSOR-LESS CONTROL SCHEME}

In critical applications of induction motor like compressors, blowers, fans, machine tool, nuclear power plants, off-shore pumping stations and electric vehicles; sensor-less controlled technique could achieve excellent performance in terms of efficiency and energy savings. Sensor-less induction motor drives operate without speed sensor and thus are helpful in cost saving and to achieve high reliability [73]. The terminal quantities such as voltage and current are used to estimate the speed. This section of the paper briefly describe the sensor-less control methods for induction motor drive for the purpose of energy saving and sustainable reliability. As described in Figure 1, sensor-less control techniques could be divided into two categories 1) Model based scheme 2) Signal injection scheme. Details of both schemes has been given below.

\subsection{Model Based Scheme}

The mathematical model of the induction motor in general reference frame could be described by Equation (1) to (4). This mathematical representation of the induction motor could be used in sensor-less control schemes to estimate the speed of the induction motor provided that all parameters of the motor are known [73-75].

$$
\begin{aligned}
& V_{s}=R_{s} I_{s}+\frac{d \Psi_{s}}{d t}+j \omega_{y} \Psi_{s} \\
& 0=R_{r} I_{r}+\frac{d \Psi_{r}}{d t}+j\left(\omega_{y}-\omega_{r}\right) \Psi_{s} \\
& \Psi_{s}=L_{s} I_{s}+L_{m} I_{r} \\
& \Psi_{r}=L_{r} I_{r}+L_{m} I_{s}
\end{aligned}
$$

In open loop speed estimation, Equation (1) is integrated to get the stator flux and from stator flux information one can calculate rotor flux [73]. The limitations of the open loop speed estimation are its sensitivity to the stator and rotor resistance and inductance. Variation in these parameters from nominal values will degrade the performance of the open loop speed estimator [73, 74]. To overcome this issue, closed-loop speed estimator or closed-loop observer could be used. Example of such type of estimators are; $i$ ) Model Reference Adaptive System (MRAS): The block diagram of the MRAS is sown in Figure 8 [73]. If the error signal is minimized then the estimated speed will equal to the actual speed. It was reported in [76-81] that MRAS could give better performance with the minimum speed range of 30-100 rpm. However, due to environmental noise and non-linearity of the power converters, MRAS could not give satisfactory results for speed less than $30 \mathrm{rpm}$. ii) Full or Reduced Order Observer: It has the capability to estimate robust speed at low speed operations of the motor [82-86]. iii) Extended Kalman Filter: It is a stochastic approach for speed estimation of the induction motor. The stochastic method solves the estimation problems through use of measurement errors, modeling errors, random disturbances, and computational inaccuracies of the system. This method can estimate the non-measured parts of a system through a minimum covariance error that leads to optimal estimated states [87-92]. iv) Sliding Mode Observer (SMO): The key features of the sliding mode observer are its easy implementation, less restrictive design, simplicity, small computations and robustness to parameter variations [93]. These features make SMO an effective estimator. However, SMO performance is affected by chattering phenomenon [94-99]. The block diagram of the SMO is shown in Figure 9. 


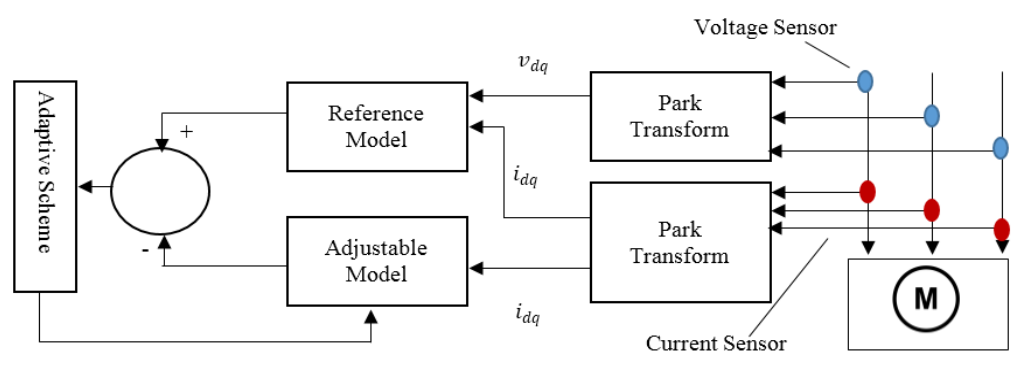

Figure 8. The Block Diagram of the MRAS for Speed Estimation

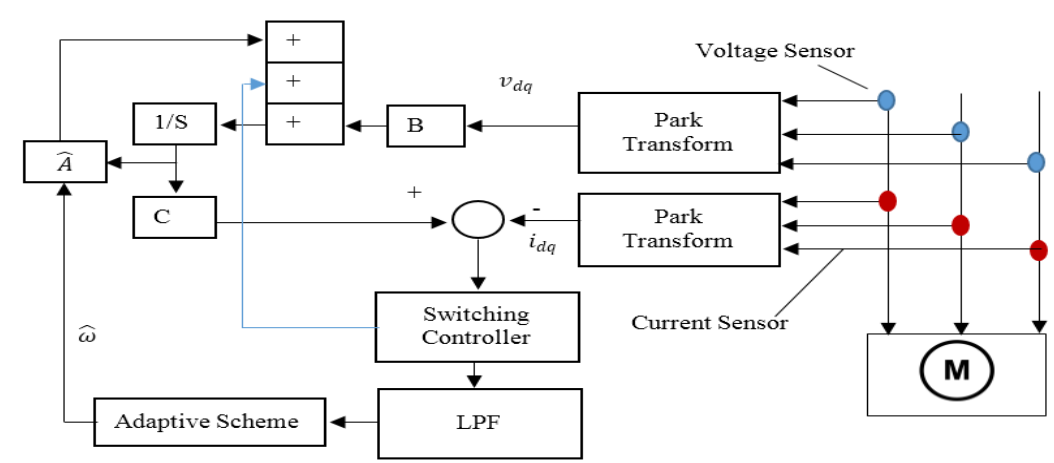

Figure 9. The Block Diagram of the SMO for Speed Estimation

\subsection{Signal Injection Scheme (SIS)}

A relatively new approach based on signal injection has gained attention of researchers in recent decade because the model based speed estimation technique has issues of performance degradation due to parameter variations and rotor speed estimation problem at zero stator frequency. SI method is based on the injection of low level signals in the induction motor [100]. The anisotropy of the machines will generate the current and voltage through which the speed information could be extracted. The magnitude and frequency of the injected signal should be selected carefully [101]. Smaller the magnitude of the injected signal, smaller will be the signal to noise ratio, while the injected signal with larger magnitude will create torque ripples. Similarly, if the frequency of the injected signal is small then it would be difficult to segregate it from the fundamental frequency signal. Thus a trade-off should be made in selecting the frequency and magnitude of the injected signal. The challenges in this method are to tackle poor signal to noise ratio, low spectral separation and to achieve required frequency tracking. These challenges could be addressed through modern signal processing techniques $[102,103]$. The general block diagram of the SIS is shown in Figure 10.

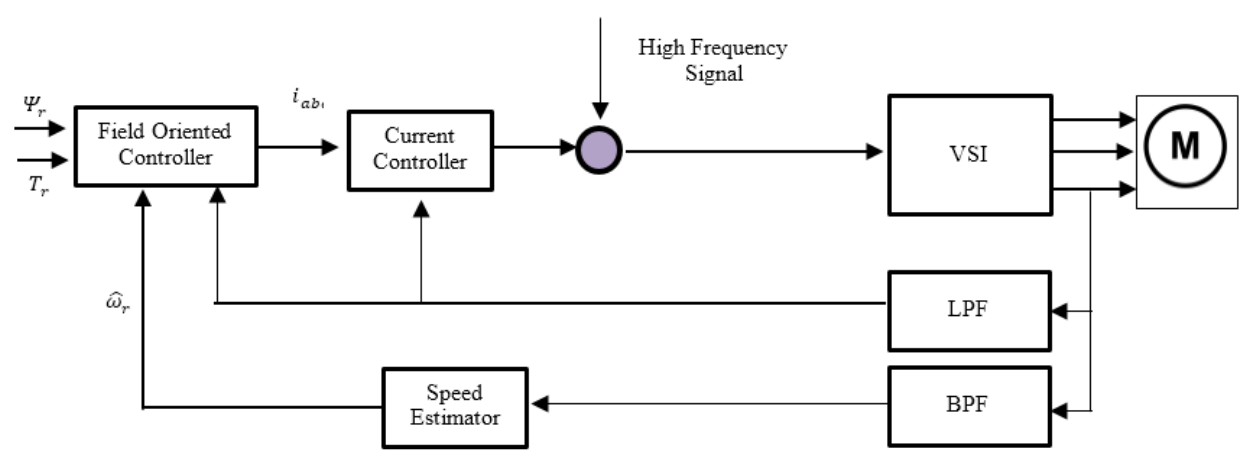

Figure 10. The Block Diagram of the Signal Injection Scheme for Speed Estimation 


\section{OPTIMIZATION TECHNIQUES FOR THE MOTOR CONTROLLER}

Optimization algorithms were developed to improve the performance of the controller. These algorithms were developed mainly based on the principle of biology- and physics-based algorithms. The biology-based algorithms are classified as genetic algorithm (GA), bee colony algorithm (BCA), harmony search algorithm (HSA), particle swarm optimization (PSO), firefly algorithm (FA), bacteria foraging optimization (BFO), lightning search algorithm (LSA), cuckoo search algorithm (CSA), colony optimization algorithm (ACO), and backtracking search algorithm (BSA). The physics-based algorithms are classified as chaotic optimization algorithm (COA), simulated annealing (SA) and gravitational search algorithm (GSA) $[8,104]$. This section of the paper, briefly describes some important and commonly used optimization algorithms and then the use of optimization algorithms for motor control applications has been presented.

\subsection{Description of Optimization Algorithms}

\subsubsection{Genetic Algorithm}

Genetic algorithm is a stochastic global adaptive search optimization technique which works as a population containing a number of chromosomes and an objective function is used for each chromosome to find a solution to the problem $[38,104,105]$. The architecture of the GA is shown in Figure 11.

Some of the applications of the GA are:

1. GA is used to find the best parameter value of rational function [106].

2. GA is used in a control system on an electric distribution network, to improve the reliability and power quality of distribution systems $[107,108]$.

3. In photo voltaic applications, it is used for maximum power point tracking (MPPT) to improve the energy harvesting capability of a PV system [109].

Some of the limitations of the GA algorithm are:

1. It cannot guarantee the identification of global minimum.

2. It operates on trial and error procedure and needs much more time to fine tune all parameters [110]

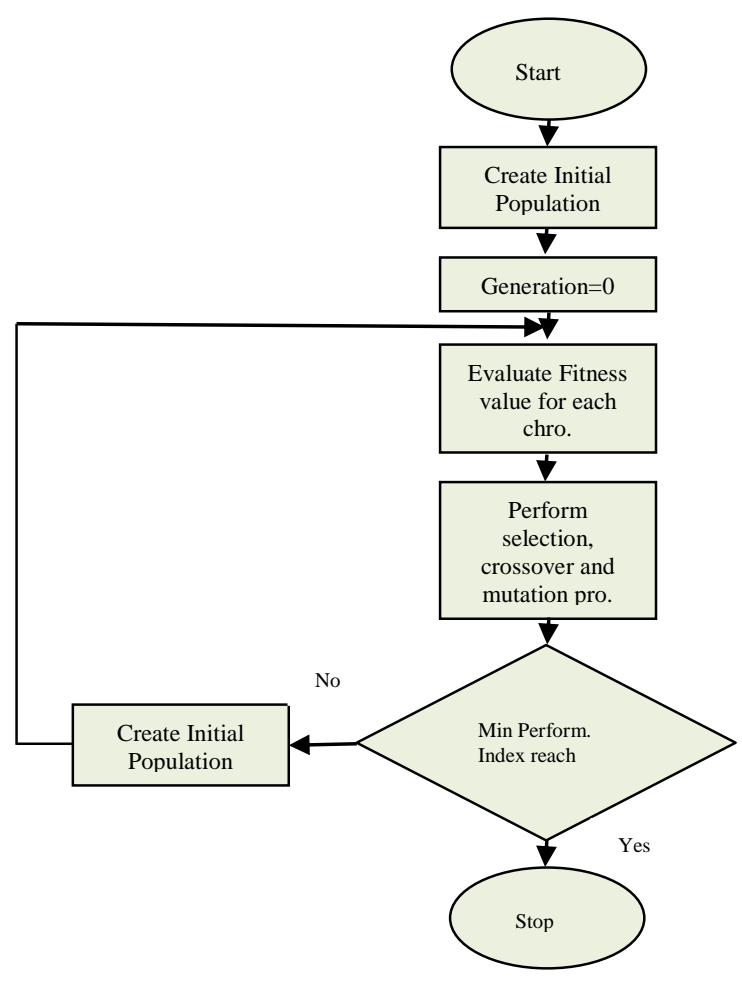

Figure 11. Genetic Algorithm Flowchart

\subsubsection{Gravitational Search Algorithm}

Gravitational search algorithm (GSA), was proposed by [169], and it depends on the law of gravity and mass interactions. GSA was developed using the laws of motion and Newtonian gravity [111]. GSA has 
the fast convergence for solution. However, it could be easily trapped in local minima and it has weakness in strategy to diversify the population of the algorithm [112,113]. Some of the applications of the GSA for optimization algorithms are listed below:

1. It was used by [114] to enhance the performance of the hydrothermal scheduling.

2. GSA was used by [112] to improve the control of the induction generator.

3. GSA was implemented by [115] to solve different optimal power flow problems.

4. It was reported in [116] that the GSA could be used to enhance the load frequency control of multi-area power system.

5. In [117], solve the identification problem for turbine regulation under load and no-load conditions using GSA.

\subsubsection{Particle Swarm Optimization}

PSO was developed by Eberhart and Kennedy (1995). It is an evolutionary computation technique which work on principal of the social behavior of bird flocking. The PSO algorithm is designed to search the space for particles in two different locations. The first location also known as local best, is the best point where the swarm finds the current iteration. The second location also known as global best, is the best point found through all previous iterations. The velocity and position of particles are the two factors used for the development PSO algorithm. PSO has many advantages like its robustness, capability to solve complex optimization problems, simple algorithm, easy to implement, fast convergence and its global exploration capability [118, 119]. However, PSO could be easily trapped in local minima, and it improperly selects control parameters, resulting in poor solution [120].

\subsubsection{Lightening Search Algorithm}

Lightening search algorithm was proposed by Shareef et al. [121] and it is a modern optimization technique used to achieve desired goals. It works on the principal of a step leader propagation mechanism called "lightning," as shown in Figure 12.

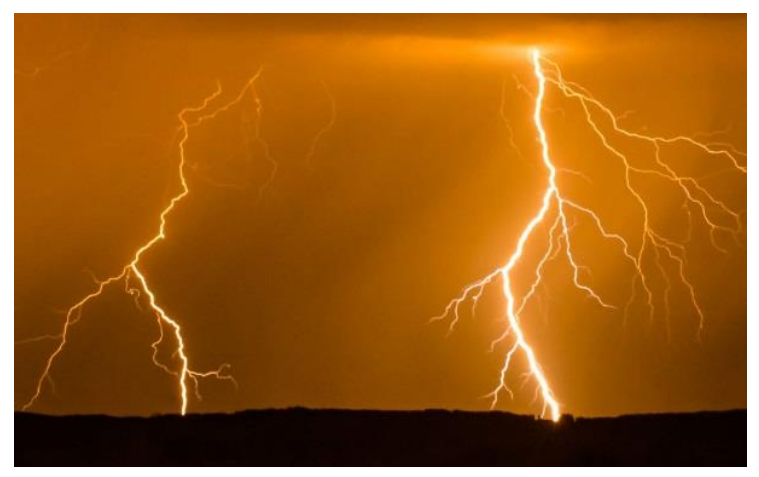

Figure 12. Step Leaders from Lightening

Lightening search algorithm use the fast particles, which are called projectiles. LSA operational mechanism consists of three steps: 1) Projectile and step leader propagation, each projectile is considered as the initial population size. The projectile term in LSA is similar to the particle and agent term in PSO and GSA techniques, respectively [121]. 2) Projectile properties, 3) Projectile modeling and movement. Compared to other optimization methods, LSA has the fast convergence for solution. This is due to the fact that LSA is inspired by natural phenomenon of lightning. However, it is time consuming as it requires searching for the best new position of the step leader [121].

\subsubsection{Backtracking Search Algorithm}

Backtracking search algorithm optimization technique, is computational technique used for producing a trial population with two new crossovers and mutation operators. BSA was invented by Civicioglu [122]. BSA has been proven to be one of the best and powerful optimization techniques because it has sturdy exploration and exploitation capabilities. BSA algorithm consist of the following parts: 1) Initialization, 2) Selection-I 3) Mutation 4) Crossover 5) Selection-II. Researchers have utilized BSA algorithm for various applications. For example, the design of the operational amplifier circuits using BSA has been reported in 
[123]. In [124, 125], BSA was used to enhance the power flow of high-voltage DC power systems. Similarly, BSA was used to solve economic dispatch problems and to investigate the best position for distributed generators placement [126, 127]. Due to usage of dual computation algorithm, BSA has long computational time [122].

\subsection{Applications of Optimization Techniques in Motor Control}

Many control applications utilize optimization algorithms for the improvement of the efficiency and performance. Some of the previous research related to development of control methods using optimization algorithms has been briefly described in this section. For example, the optimal speed tracking of an induction motor was achieved through an optimized GA based Fuzzy Logic Controller and Proportional Integral controller [128]. Similarly, for speed control in the indirect field oriented control, an optimized GA based Proportional Integral controller was used to design the fuzzy gain scheduling [129]. The factor selection for the input of membership functions was achieved through an optimized GA based Fuzzy Logic Controller [130]. In a similar work, the best parameters for the Proportional Integral controller were calculated using GA based Proportional Integral controller [131, 132]. GA was used in hybrid FLC-PI controller for the prototype implementation using dSPACE, and to improve the performance of an induction motor [133]. In a digital signal processing tool kit, GA was used to optimize the sliding surface slope and thickness of the boundary layer [11]. In the development of the V/f control for induction motor, GA was used to improve ANFIS speed controller for selecting best PI values [22]. In selecting the optimal intelligent model parameters for high-power permanent magnet synchronous motor, Particle Swarm Optimization technique was used by [134]. In a similar work, Particle Swarm Optimization technique was used to optimize nine-rule Fuzzy Logic Controller for maximum power point tracking in a grid-connected inverter [46]. In [135] Particle Swarm Optimization technique was utilized to improve Fuzzy Logic Controller for finding the best values of the input membership function for maximum power point tracking. In [136], the speed control of induction motor was improved using an optimized PSO based FLC controller. In a related study, PSO was used to optimize FLC controller for enhancing the speed control of a quasi-Z source DC/DC converter-fed drive through identification of the best values for the scaling factor of the input and output [137, 138]. The performance of the PID controller and hybrid FLC-PI controller was improved by using the Genetic Algorithm and Particle Swarm Optimization technique [18]. The optimal torque control of the induction motor using PI controller was achieved by [48] using hybrid GA-PSO optimization techniques. The performance of the PID controller for finding the best PID parameters for DC torque motor system was improved using Backtracking Search Algorithm optimization technique [139, 140]. The summary of optimization techniques used in improving the motor control performance has been given in Table 2 .

Table 2. Summary of the Optimization Techniques for Improving the Controller Performance

\begin{tabular}{ccc}
\hline Reference & Control Technique & Optimization Technique \\
\hline 11 & SMC & GA \\
22 & PI & GA \\
18 & PID & GA, PSO \\
46 & FLC & PSO \\
48 & PI & Hybrid GA, PSO \\
128 & PI, FLC & GA \\
129 & PI & GA \\
130 & FLC & GA \\
131 & ANN & GA \\
133 & Hybrid PI-FLC & GA \\
135 & FLC & PSO \\
136 & ANFIS & PSO \\
137 & FLC & PSO \\
139 & PID & BSA \\
\hline
\end{tabular}

\section{CRITICAL ANALYSIS}

Although the performance of the induction motor control system could be improved through various controller techniques. However, there are some challenges in implementing the control techniques.

1. For example, implementation of conventional controllers (PID, FLC) for induction motor control require suitable parameters of induction motor which are difficult to obtain. Furthermore, the mathematical models used in conventional controllers are highly sensitive to the parameter variation. A sudden change in load, temperature or reference speed, will deteriorate the performance of the controller $[8,14,19,20$, 
64 141]. These issues in conventional controllers could be addressed through use of optimization techniques.

2. The increase of carbon in the atmosphere has has threaten the environment safety and researchers are focusing on energy conservation methods to reduce the carbon contents in the atmosphere. In this scenario, development of electric vehicles has gain much attention [142]. Induction motors are being used in modern electric vehicles and it is important to develop a control scheme to enhance the performance of the induction motor control. Although FOC has been the famous control strategy for induction motor but it needs intensive computation, has low torque response and also produces torque ripples. To overcome these issue of FOC for electric vehicle applications, direct torque control technique for induction motor control could be alternate choice as it needs simple computation and has fast dynamic response [143-147].

3. Although the scalar and vector control schemes has been shown to be effective control techniques for improving the performance of the induction motor control, however, these control schemes use costly speed sensor to measure the rotor speed. As the installation and maintenance of speed sensor requires access to the motor and access to the motor is not possible in some critical application like nuclear power plants, off-shore pumping stations, blowers, fans. Thus, the sensor-less control scheme could be an alternative to enhance reliability, and to reduce cost for such type of applications.

In sensor-less control scheme, model based control method is best suitable for medium to high speed applications while signal injection method is best suitable for low speed applications. Combination of both will generate good performance for all variable speed drives.

\section{CONCLUSION}

Induction motors have variety of applications in energy conversion. Proper control scheme for induction motor could enhance their efficiency, performance and eventually could save energy. This paper has attempt to review various control techniques and has presented their advantages and limitations. It has been shown that the limitations of the conventional control techniques could be overcome through optimization techniques and it is preferable to use direct torque control technique for the control applications where fast dynamic response is desired like in electric vehicles, turbines and railway tractions. It has been concluded that sensor-less control scheme is a cost effective and highly reliable control method for applications where access to the motor for speed sensor installation is not possible.

\section{REFERENCES}

[1] M. Magzoub, N. Saad, R. Ibrahim and M. Irfan, An experimental demonstration of hybrid fuzzy-fuzzyspacevector control on AC variable speed drives, Neural Computing \& Applications, pp. 1-16, 2017.

[2] N. Saad and M. Arro, "A PLC-based modified-fuzzy controller for PWM-driven induction motor drive with constant V/Hz ratio control," Robotics and Computer-Integrated Manufacturing, vol. 28, pp. 95-112, 2012.

[3] Suetake M, da Silva IN, Goedtel A. Embedded DSP-based compact fuzzy system and its application for induction-motor speed control. IEEE Transactions on Industrial Electronics, vol. 58, pp. 750-60, 2011.

[4] CMFS Reza, Islam MD, Mekhilef S. A review of reliable and energy efficient direct torque controlled induction motor drives. Renewable Sustainable Energy Review, vol. 37, pp. 919-32, 2014.

[5] Dos Santos TH, Goedtel A, da Silva SAO, Suetake M. Scalar control of an induction motor using a neural sensorless technique. Electrical Power Systm Research, vol. 108, pp. 322-30, 2014.

[6] Alsofyani IM, Idris NRN. A review on sensorless techniques for sustainable reliablity and efficient variable frequency drives of induction motors. Renewable Sustainable Energy Review, vol. 24, pp. 111-21 2013.

[7] Sarhan H. Efficiency optimization of vector-controlled induction motor drive. International Journal of Advance Engineering Technology, vol. 7, 2014.

[8] M.A. Hannana, Jamal A. Ali, Azah Mohamed, Aini Hussain, Optimization techniques to enhance the performance of induction motor drives: a review, Renewable and Sustainable Energy Reviews, 2017.

[9] Allirani S, Jagannathan V. Direct torque control technique in induction motor drives - a review. Journal of Theory \& Applications of Information Technology, vol. 60, 2014.

[10] Rong-Jong W, Jeng-Dao L, Kuo-Min L. Robust decoupled control of direct fieldoriented induction motor drive. 5th Asian Control Conference, pp. 1346-1353, 2004.

[11] Demirtas M. DSP-based sliding mode speed control of induction motor using neuro-genetic structure. Expert System Applications, vol. 36, pp. 33-40, 2009.

[12] Hedjar R, Boucher P, Dumur D. Robust nonlinear receding-horizon control of induction motors. International Journal of Electrical Power Energy System, vol. 46, pp. 353-65, 2013.

[13] Sutikno T, Idris NRN, Jidin A. A review of direct torque control of induction motors for sustainable reliability and energy efficient drives. Renewable Sustainable Energy Review, vol. 32, pp. 548-58, 2014.

[14] Lekhchine S, Bahi T, Soufi Y. Indirect rotor field oriented control based on fuzzy logic controlled double star induction machine. International Journal of Electrical Power Energy System, vol. 57, pp. 206-11, 2014. 
[15] Ngo PD, Shin YC. Gain estimation of nonlinear dynamic systems modeled by an FBFN and the maximum output scaling factor of a self-tuning PI fuzzy controller. Eng Appl Artif Intell, vol. 42, pp. 1-15, 2015.

[16] Hazzab A, Bousserhane IK, Zerbo M, Sicard P. Real time implementation of fuzzy gain scheduling of PI controller for induction machine control. Information Communication Technology, 1416-1421, 2006.

[17] Mutlag AH, Shareef H, Mohamed A, Hannan M, Abd Ali J. An improved fuzzy logic controller design for PV inverters utilizing differential search optimization. International Journal of Photonics 2014.

[18] Pan I, Das S, Gupta A. Tuning of an optimal fuzzy PID controller with stochastic algorithms for networked control systems with random time delay. ISA Transactions, vol. 50, pp. 28-36, 2011.

[19] Ali JA, Hannan MA, Mohamed A, Abdolrasol MGM. Fuzzy logic speed controller optimization approach for induction motor drive using backtracking search algorithm. Measurement, vol. 78, pp. 49-62, 2016.

[20] Ustun SV, Demirtas M. Optimal tuning of PI coefficients by using fuzzy-genetic for V/f controlled induction motor. Expert System Applications, vol. 34, pp. 2714-2720, 2008.

[21] Ali JA, Hannan MA, Mohamed A. Rule-based fuzzy and V/f control for induction motor speed responses using SVPWM switching technique. Przeglad Elektrotech, 2015;91:133-6.

[22] Ustun SV, Demirtas M. Modeling and control of V/f controlled induction motor using genetic-ANFIS algorithm. Energy Conversion Management, vol. 50, pp.786-791, 2009.

[23] Saad N, Arrofiq M. A PLC-based modified-fuzzy controller for PWM-driven induction motor drive with constant V/Hz ratio control. Robot Computer Integrated Manufacturing, vol. 28, pp. 95-112, 2012.

[24] Zidani F, Saïd MSN, Abdessemed R, Diallo D, Benbouzid MEH. A fuzzy technique for loss minimization in scalar-controlled induction motor. Electric Power Component System, vol. 30, pp. 625-635 2002.

[25] H. S.r and R.J. Richards, "Sliding mode control of an electrically powered industrial robot," IEE Proceedings control theory and applications, pp. 207-225, 1992.

[26] A. Engineering, "Discrete Sliding Mode Controller for Pressure Control with an Electrohydraulic Servovalve," Aerospace Engineering, pp. 1-5, 1998.

[27] M.A. Jaradat, M.I. Awad, and B.S. El-khasawneh, "Genetic-fuzzy sliding mode controller for a de servomotor system," The 8th International Symposium on Mechatronics and its Applications (ISMA), 2012.

[28] Y. Zheng, Y. Jing, R. Hou, and T. Ren, "Discrete-Time Fuzzy Sliding Mode Control of Nonlinear Systems *," Design, pp. 997-1001, 2006.

[29] Y.U. Yuntao, L.I. Yan, and Y.I. Zhenyong, "A Novel Induction Motor With Fuzzy Sliding-Mode Control," Proceedings of the 30th Chinese Control Conference, pp. 1835-1838, 2011.

[30] Ali JA, Hannan MA, Mohamed A. PSO algorithm for three phase induction motor drive with SVPWM switching and V/f control. IEEE International Conference on power and energy (PECon), pp. 250-254, 2014.

[31] Merabet Boulouiha H, Allali A, Laouer M, Tahri A, Denaï M, Draou A. Direct torque control of multilevel SVPWM inverter in variable speed SCIG-based wind energy conversion system. Renewable Energy, vol. 80, pp.140-52, 2015.

[32] Durgasukumar G, Pathak MK. Comparison of adaptive neuro-fuzzy-based spacevector modulation for two-level inverter. International Journal of Electrical Power Energy Systems, vol. 38, pp. 9-19, 2012.

[33] Raja Singh R, Raj Chelliah T, Agarwal P. Power electronics in hydro electric energy systems - a review. Renewable Sustainable Energy Review, vol. 32, pp. 944-59, 2014.

[34] Karaboga D. An idea based on honey bee swarm for numerical optimization. Technical report-tr06, Erciyes university, engineering faculty, computer engineering department; 2005.

[35] Dorigo M, Maniezzo V, Colorni A. Ant system: optimization by a colony of cooperating agents. Syst, Man, Cybern, Part B: Cybern, IEEE Transactions on cybernetwork, vol. 26, pp.29-41, 1996.

[36] Eslami M, Shareef H, Taha MR, Khajehzadeh M. Adaptive particle swarm optimization for simultaneous design of UPFC damping controllers. International Journal Electrical Power Energy Systems, vol. 57, pp. 116-28, 2014.

[37] Goldberg DE. Genetic algorithms in search optimization and machine learning. Menlo Park: Addison-wesley Reading; 1989.

[38] Whitley D. A genetic algorithm tutorial. Stat Comput, vol. 4, pp. 65-85, 1994.

[39] Storn R, Price K. Differential evolution-a simple and efficient heuristic for global optimization over continuous spaces. Journal of Glob Optimization, vol. 11, pp. 341-59, 1997.

[40] Fang D, Rastko Z, Said A-S, David M. Induction motor parameter estimation using sparse grid optimization algorithm. IEEE Transactions on Industry Informatics, vol. 12, no. 4, pp. 1453-1461, 2016.

[41] Sakthivel VP, Bhuvaneswari R, Subramanian S. Multi-objective parameter estimation of induction motor using particle swarm optimization. Eng Appl Artif Intell, vol. 23, no. 3, pp. 302-312, 2010.

[42] Zheng H, Kay H. A method of constraint handling for speed-controlled induction machines. IEEE Transactions on Industrial Electronics, vol. 63, no. 7, pp. 4061-4072, 2017.

[43] Ali JA, Hannan M, Mohamed A PSO algorithm for three phase induction motor drive with SVPWM switching and V/f control. IEEE International Conference on Power and Energy (PECon), 2014.

[44] Ali JA, Hannan M, Mohamed A. Improved indirect field-oriented control of induction motor drive based PSO algorithm. Jurnal Teknologi, vol. 78, 2016.

[45] Ali JA, Hannan M, Mohamed A. Gravitational search algorithm based tuning of a PI speed controller for an induction motor drive. IOP Conference Series: Earth and Environmental Science: IOP Publishing. pp. 1200112004, 2016.

[46] Letting LK, Munda JL, Hamam Y. Optimization of a fuzzy logic controller for PV grid inverter control using Sfunction based PSO. Sol Energy, vol, 86, pp. 1689-700, 2012.

[47] Chebre Mh, Meroufel A, Bendaha Y. Speed control of induction motor using genetic algorithm-based PI controller. Acta Polytech Hung, vol. 8, pp. 141-53, 2011.

[48] Kim DH. GA-PSO based vector control of indirect three phase induction motor. Applied Soft Computing, vol. 7, pp. 601-611, 2007. 
[49] Christian AR, Jose RR, Samir K, Felipe V. Multiobjective fuzzy-decision-making predictive torque control for an induction motor drive. IEEE Transactions on Power Electronics, vol. 32, no. 8, pp. 6245-6260, 2017.

[50] Rodas J, Cristina M, Arahal MR, Federico B, Gregor R. Influence of Covariancebased ALS methods in the performance of predictive controllers with rotor current estimation. IEEE Transactions on Industrial Electronics, vol. 64, no. 4, pp. 2602-2607, 2017.

[51] Ahmed AA, Koh BK, Park HS, Lee K-B. Finite-control set model predictive control method for torque control of induction motors using a state tracking cost index. IEEE Transactions on Industrial Electronics, vol. 64, no. 3, pp. 1916-1928, 2016.

[52] Rockwell Automation. Energy savings with variable frequency drives,〈http://literature.rockwellautomation.com/idc/groups/literature/documents/ar/7000-ar002_-en-p.pdf); 2007.

[53] Barambones O, Alkorta P. A robust vector control for induction motor drives with an adaptive sliding-mode control law. Journal of Franklin Institute, vol. 348, pp. 300-314, 2011.

[54] Zaky MS, Khater MM, Shokralla SS, Yasin HA. Wide-speed-range estimation with online parameter identification schemes of sensorless induction motor drives. IEEE Transactionson Industrial Electronics, vol. 56, pp.1699-1707, 2009.

[55] Luo Y-C, Chen W-X. Sensorless stator field orientation controlled induction motor drive with a fuzzy speed controller. Comput Math, vol. 64, pp.1206-1216, Appl 2012.

[56] Montanari M, Peresada S, Tilli A. A speed-sensorless indirect field-oriented control for induction motors based on high gain speed estimation. Automatica, vol. 42, pp. 1637-1650, 2006.

[57] Bounar N, Boulkroune A, Boudjema F, M'Saad M, Farza M. Adaptive fuzzy vector control for a doubly-fed induction motor. Neurocomputing, vol. 151, pp. 756-769, 2015.

[58] Maiti S, Chakraborty C. A new instantaneous reactive power based MRAS for sensorless induction motor drive. Simulation Modelling Practice Theory, vol. 18, pp. 1314-1326, 2010.

[59] Jemli M, Ben Azza H, Gossa M. Real-time implementation of IRFOC for Single-Phase Induction Motor drive using dSpace DS 1104 control board. Simulation Modelling Practice Theory, vol. 17, pp. 1071-1080, 2009.

[60] Azza HB, Jemli M, Boussak M, Gossa M. High performance sensorless speed vector control of SPIM drives with on-line stator resistance estimation. Simulation Modelling Practice Theory, vol. 19, pp. 271-282, 2011.

[61] Arun Dominic D, Chelliah TR. Analysis of field-oriented controlled induction motor drives under sensor faults and an overview of sensorless schemes. ISA Transactions, vol. 53, pp. 1680-1694, 2014.

[62] Marino R, Tomei P, Verrelli CM. Adaptive field-oriented control of synchronous motors with damping windings. Europeon Journal of Control, vol. 14, pp. 177-195, 2008.

[63] Hong C-M, Cheng F-S, Chen C-H. Optimal control for variable-speed wind generation systems using general regression neural network. International Journal of Electric Power Energy Systems, vol. 60, pp. 14-23, 2014.

[64] Arrouf M, Bouguechal N. Vector control of an induction motor fed by a photovoltaic generator. Applied Energy, 74:159-67, 2003.

[65] Arahal MR, Duran MJ. PI tuning of five-phase drives with third harmonic injection. Control Engineering Practice, vol. 17, pp. 787-797, 2009.

[66] Souza Júnior ABd, Diniz EdC, Honório DdA, Barreto LHSC, dos Reis LLN. Hybrid control robust using logic fuzzy applied to the position loop for vector control to induction motors. Electric Power Component System, vol. 42, pp. 533-543, 2014.

[67] Vas P. Sensorless vector and direct torque control. New York: Oxford University Press; 1998.

[68] Takahashi I, Noguchi T. A new quick-response and high-efficiency control strategy of an induction motor. IEEE Transactions on Industrial Applications, pp. 820-827, 1986.

[69] Baader U, Depenbrock M, Gierse G. Direct self control (DSC) of inverter-fed induction machine: a basis for speed control without speed measurement. IEEE Transactions on Industrial Applications, vol, 28, pp. 581$588,1992$.

[70] Depenbrock M. Direct self-control (DSC) of inverter-fed induction machine. IEEE Transactions on Power Electronics, vol. 3, pp. 420-429, 1988.

[71] Depenbrock M. Direct self-control of the flux and rotary moment of a rotaryfield machine. Google patents; 1987.

[72] C.M.F.S. Reza n, Md. Didarul Islam, Saad Mekhilef, A review of reliable and energy efficient direct torque controlled induction motor drives, Renewable and sustainable energy reviews, vol. 37, pp. 919-932, 2014.

[73] Ibrahim M. Alsofyani n, N.R.N. Idris, A review on sensorless techniques for sustainable reliablity and efficient variable frequency drives of induction motors, Renewable and Sustainable Energy Reviews, vol. 24, pp. 111-121, 2013.

[74] Oguz Y, Dede M. Speed estimation of vector controlled squirrel cage asynchronous motor with artificial neural networks. Energy Conversion and Management, vol. 52, pp. 675-686, 2011.

[75] Barut M, Bogosyan S, Gokasan M. Experimental evaluation of braided EKF for sensorless control of induction motors. IEEE Transaction on Industrial Electronics, vol. 55, pp. 620-632, 2008.

[76] Maurizio C, Marcello P, Giansalvo C, Grard-Andr C. Sensorless control of induction machines by a new neural algorithm: the TLS EXIN neuron. IEEE Transactions on Industrial Electronics, vol. 54, pp. 127-149, 2007.

[77] Li Y, Qin W. Low speed performence improvement of sensorless IM control system based on MRAS and NN flux observers. In: Proceedings of IEEE international conference on intelligent computing and intelligent systems (ICIS), vol. 2, pp. 421-425, 2010.

[78] Orlowska-Kowalska T, Dybkowski M. Stator-current-based MRAS estimator for a wide range speed-sensorless induction-motor drive. IEEE Transactions on Industrial Electronics, vol. 57, pp. 1296-1308, 2010.

[79] Gadoue SM, Giaouris D, Finch JW. A new fuzzy logic based adaptation mechanism for MRAS sensorless vector control induction motor drives. In: Proceedings of $4^{\text {th }}$ IET conference on power electronics, machines and drives, pp. 179-183, 2008. 
[80] Sayouti Y, Abbou A, Akherraz M, Mahmoudi H. Sensor less low speed control with ANN MRAS for direct torque controlled induction motor drive. In: Proceedings of international conference on power engineering, energy and electrical drives (POWERENG), pp. 1-5, 2011.

[81] Gadoue SM, Giaouris D, Finch JW. MRAS sensorless vector control of an induction motor using new slidingmode and fuzzy-logic adaptation mechanisms. IEEE Transaction on Energy Conversion, vol. 25, pp. 394-402, 2010.

[82] Cirrincione M, Pucci M, Cirrincione G, Capolino GA. An adaptive speed observer based on a new total leastsquares neuron for induction machine drives. IEEE Transaction on Industry application, vol. 42, pp. 89-104, 2006.

[83] Davari SA, Khaburi DA, Fengxiang W, Kennel RM. Using full order and reduced order observers for robust sensorless predictive torque control of induction motors. IEEE Transactions on Power Electronics, vol. 27, pp. 3424-3433, 2012.

[84] Harnefors L, Hinkkanen M. Complete stability of reduced-order and full-order observers for sensorless IM drives. IEEE Transactions on Industrial Electronics, vol. 55, pp. 1319-1329, 2008.

[85] Kubota H, Matsuse K, Nakano T. DSP-based speed adaptive flux observer of induction motor. IEEE Transactions on Industry Applications, vol. 29, pp. 344-348, 1993.

[86] Salmasi FR, Najafabadi TA. An adaptive observer with online rotor and stator resistance estimation for induction motors with one phase current sensor. IEEE Transactions on Energy Conversion, vol. 26, pp. 959-966, 2011.

[87] Barut M, Demir R, Zerdali E, Inan R. Real-time implementation of Bi inputextended kalman filter-based estimator for speed-sensorless control of induction motors. IEEE Transactions on Industrial Electronics, vol. 59, pp. 4197-4206, 2012.

[88] Buyamin S, Finch JW. Comparative study on optimising the EKF for speed estimation of an induction motor using simulated annealing and genetic algorithm. In: Proceedings of IEEE international electric machines \& drives conference, IEMDC '07 2; , pp. 1689-94, 2007.

[89] Alsofyani IM, Idris NRN, Sutikno T, Alamri YA. An optimized extended kalman filter for speed sensorless direct troque control of an induction motor. In: Proceedings of IEEE international conference on power and energy (PECon), pp. 319-324 2012.

[90] Ozsoy EE, Gokasan M, Bogosyan S. Simultaneous rotor and stator resistance estimation of squirrel cage induction machine with a single extended kalman filter. Turkish Journal of Electrical Engineering and Computer Sciences, vol. 18, pp. 853-863, 2010.

[91] Gherram K, Yazid K, Menaa M. Sensorless indirect vector control of an induction motor by ANNs observer and $E K F$. In: Proceedings of 18th Mediterranean conference on control \& automation (MED), pp. 521-6, 2010.

[92] Danan S, Wenli L, Lijun D, Zhigang L. Speed sensorless induction motor drive based on EKF and G-1 model. In: Proceedings of international conference on computer distributed control and intelligent environmental monitoring (CDCIEM), pp. 290-294, 2011.

[93] Lascu C, Boldea I, Blaabjerg F. Very-low-speed variable-structure control of sensorless induction machine drives without signal injection. IEEE Transactions on Industry Applications, vol. 41, pp. 591-598, 2005.

[94] Comanescu M. An induction-motor speed estimator based on integral slidingmode current control. IEEE Transactions on Industrial Electronics, vol. 56, pp. 3414-3423, 2009.

[95] Derdiyok A. Speed-sensorless control of induction motor using a continuous control approach of sliding-mode and flux observer. IEEE Transactions on Industrial Electronics, vol. 52, pp. 1170-1176, 2005.

[96] Ghanes M, Gang Z. On sensorless induction motor drives: sliding-mode observer and output feedback controller. IEEE Transactions on Industrial Electronics, vol. 56, pp. 3404-3413, 2009.

[97] Vieira RP, Gastaldini CC, Azzolin RZ, Grundling HA. Discrete-time sliding mode approach for speed estimation of symmetrical and asymmetrical induction machines. In: Proceedings of 37th annual conference on IEEE industrial electronics society IECON, p. 1819-24. 2011.

[98] Yongchang Z, Jianguo Z, Wei X, Jiefeng H, Dorrell DG, Zhengming Z. Speed sensorless stator flux oriented control of three-level inverter-fed induction motor drive based on fuzzy logic and sliding mode control. In: Proceedings of 36th annual conference on IEEE industrial electronics society IECON, pp. 2932-2937, 2010.

[99] Zaky MS, Khater M, Yasin H, Shokralla SS. Very low speed and zero speed estimations of sensorless induction motor drives. Electric Power Systems Research, vol. 80, pp.143-151, 2010.

[100] Finch JW, Giaouris D. Controlled AC electrical drives. IEEE Transactions on Industrial Electronics, vol. 55, pp. 481-491, 2008.

[101] Guanghui W, Hofmann HF, El-Antably A. Speed-sensorless torque control of induction machine based on carrier signal injection and smooth-air-gap induction machine model. IEEE Transactions on Energy Conversion, vol. 21, pp. 699-707, 2006.

[102] Giaouris D, Finch JW, Ferreira OC, Kennel RM, El-Murr GM. Wavelet denoising for electric drives. IEEE Transactions on Industrial Electronics, vol. 55, pp. 543-550, 2008.

[103] Pineda-Sanchez M, Riera-Guasp M, Antonino-Daviu JA, Roger-Folch J, Perez-Cruz J, Puche-Panadero R. Diagnosis of induction motor faults in the fractional Fourier domain. IEEE Transactions on Instrumentation and Measurement, vol. 59, pp. 2065-2075, 2010.

[104] Suganthi L, Iniyan S, Samuel AA. Applications of fuzzy logic in renewable energy systems - a review. Renewable Sustainable Energy Review, vol. 48. Pp. 585-607, 2015.

[105] Singh B, Mukherjee V, Tiwari P. Genetic algorithm for impact assessment of optimally placed distributed generations with different load models from minimum total MVA intake viewpoint of main substation. Renewable Sustainable Energy Review, vol. 57, pp. 1611-1636, 2016.

[106] Irshad M, Khalid S, Hussain MZ, Sarfraz M. Outline capturing using rational functions with the help of genetic algorithm. Appl Math Comput, vol. 274, pp. 661-678, 2016. 
[107] Storti GL, Paschero M, Rizzi A, Frattale Mascioli FM. Comparison between timeconstrained and timeunconstrained optimization for power losses minimization in Smart Grids using genetic algorithms. Neurocomputing, vol. 170, pp. 353-367, 2015.

[108] Gupta N, Swarnkar A, Niazi KR. Distribution network reconfiguration for power quality and reliability improvement using Genetic algorithms. International Journal of Electric Power Energy Systems, vol. 54, pp. 664-671, 2014.

[109] Daraban S, Petreus D, Morel C. A novel MPPT (maximum power point tracking) algorithm based on a modified genetic algorithm specialized on tracking the global maximum power point in photovoltaic systems affected by partial shading. Energy, vol. 74, pp. 374-388, 2014.

[110] Tabassum M, Mathew K. A genetic algorithm analysis towards optimizationsolutions. Int J Digit Inf Wirel Commun (IJDIWC), vol. 4, pp. 124-142, 2014.

[111] Rashedi E, Nezamabadi-pour H, Saryazdi S. GSA: a gravitational search algorithm. Information Science, vol. 179, pp. 2232-2248, 2009.

[112] Chatterjee A, Roy K, Chatterjee D. A Gravitational Search Algorithm (GSA) based Photo-Voltaic (PV) excitation control strategy for single phase operation of three phase wind-turbine coupled induction generator. Energy, vol. 74, pp. 707-718, 2014.

[113] Soleimanpour-moghadam M, Nezamabadi-pour H, Farsangi MM. A quantum inspired gravitational search algorithm for numerical function optimization. Information Sciences, vol. 267, pp. 83-100, 2014.

[114] Bhowmik AR, Chakraborty AK. Solution of optimal power flow using non dominated sorting multi objective opposition based gravitational search algorithm. International Journal of Electric Power Energy Systems, vol. 64, pp. $1237-1250,2015$.

[115] Gouthamkumar N, Sharma V, Naresh R. Disruption based gravitational search algorithm for short term hydrothermal scheduling. Expert System Applications, vol. 42, pp. 7000-7011, 2015.

[116] Sahu RK, Panda S, Padhan S. A novel hybrid gravitational search and pattern search algorithm for load frequency control of nonlinear power system. Appl Softw Comput, vol. 29, pp. 310-327, 2015.

[117] Chen Z, Yuan X, Tian H, Ji B. Improved gravitational search algorithm for parameter identification of water turbine regulation system. Energy Convers Manag, vol. 78, pp. 306-315, 2014.

[118] Ramli L, Sam YM, Mohamed Z, Aripin MK, Ismail MF. Composite nonlinear feedback control with multiobjective particle swarm optimization for active front steering system. Jurnal Teknologi, vol. 72, 2015.

[119] Maleki A, Ameri M, Keynia F. Scrutiny of multifarious particle swarm optimization for finding the optimal size of a PV/wind/battery hybrid system. Renew Energy, vol. 80, pp. 552-63, 2015.

[120] Xi M, Sun J, Xu W. An improved quantum-behaved particle swarm optimization algorithm with weighted mean best position. Appl Math Comput, vol. 205, pp. 751-759, 2008.

[121] Shareef H, Ibrahim AA, Mutlag AH. Lightning search algorithm. Applied Soft Computing, vol. 36, pp. 315-333, 2015.

[122] Civicioglu P. Backtracking search optimization algorithm for numerical optimization problems. Applied Mathematical Computing, vol. 219, pp. 8121-844, 2013.

[123] Mallick S, Kar R, Mandal D, Ghoshal SP. CMOS analogue amplifier circuits optimisation using hybrid backtracking search algorithm with differential evolution. Journal of Experiment and Theory of Artificial Intelligence, pp. 1-31, 2015.

[124] Ayan K, Kılıç U. Optimal power flow of two-terminal HVDC systems using backtracking search algorithm. International Journal of Electric Power Energy System, vol. 78, pp. 326-335, 2016.

[125] El-Fergany A. Study impact of various load models on DG placement and sizing using backtracking search algorithm. Applied Soft Computing, vol. 30, pp. 803-811, 2015.

[126] Modiri-Delshad M, Rahim NA. Solving non-convex economic dispatch problem via backtracking search algorithm. Energy, vol. 77, pp. 372-381, 2014.

[127] Gupta V, Donepudi SR, Subrahmanyam N. Optimal placement of distributed generators in distribution system using backtracking search optimization for various load models. International Conference on Recent Developments in Control, Automation and Power Engineering (RDCAPE), pp. 350-354, 2015.

[128] Chiang C-L, Su C-T. Tracking control of induction motor using fuzzy phase plane controller with improved genetic algorithm. Electric Power System Research, vol. 73, pp. 239-247, 2005.

[129] Bousserhane IK, Hazzab A, Rahli M, Kamli M, Mazari B. Adaptive PI Controller using Fuzzy System Optimized by Genetic Algorithm for Induction Motor Control. 10th IEEE International Power Electronics Congress, pp. 1-8, 2006.

[130] Elmas C, Yigit T. Genetic algorithm based on-line tuning of a pi controller for a switched reluctance motor drive. Electr Power Component System, vol. 35, pp. 675-691, 2007.

[131] Lin FJ, Huang PK, Chou WD. A genetic algorithm based recurrent fuzzy neural network for linear induction motor servo drive. Journal of Chinese Institute of Engineering, vol. 30, pp. 801-817, 2007.

[132] Lin FJ, Huang PK, Chou WD. Recurrent-fuzzy-neural-network-controlled linear induction motor servo drive using genetic algorithms. IEEE Trans Ind Electron, vol. 54, pp. 1449-1461, 2007.

[133] Rubaai A, Castro-Sitiriche MJ, Ofoli AR. DSP-based laboratory implementation of hybrid fuzzy-PID controller using genetic optimization for high-performance motor drives. IEEE Transactions on Industry Applications, vol. 44, pp. 1977-1986, 2008.

[134] Liu L, Liu W, Cartes DA. Particle swarm optimization-based parameter identification applied to permanent magnet synchronous motors. Engineering Applied Artificial Intelligence, vol. 21, pp. 1092-1100, 2008.

[135] Cheng P-C, Peng B-R, Liu Y-H, Cheng Y-S, Huang J-W. optimization of a fuzzylogic- control-based MPPT algorithm using the particle swarm optimization technique. Energies, vol. 8, pp. 5338-5360, 2015.

[136] Mahapatra S, Daniel R, Dey DN, Nayak SK. Induction motor control using PSOANFIS. Procedia Computer Science, vol. 48, pp. 753-768, 2015. 
[137] Ranjani M, Murugesan P. Optimal fuzzy controller parameters using PSO for speed control of Quasi-Z source DC/DC converter fed drive. Applied Soft Computing, vol, 27, pp. 332-356, 2015.

[138] Ellabban O, Haitham A-R. An overview for the Z-source converter in motor drive applications. Renewable Sustainable Energy Review, vol. 61, pp. 537-555, 2016.

[139] Precup RE, Balint AD, Radac MB, Petriu EM Backtracking search optimization algorithm-based approach to PID controller tuning for torque motor systems. 9th Annual IEEE International Systems Conference (SysCon), pp. 127-132, 2015.

[140] Precup R-E, Balint A-D, Petriu EM, Radac M-B, Voisan E-I PI and PID controller tuning for an automotive application using backtracking search optimization algorithms. IEEE In: Proceedings of the 10th Jubilee International Symposium on Applied Computational Intelligence and Informatics (SACI), pp. 161-166, 2015.

[141] Zou Hongbo, Li H. Tuning of PI-PD controller using extended non-minimal state space model predictive control for the stabilized gasoline vapor pressure in a stabilized tower. Chemom Intell Lab Syst, vol. 142, pp. 1-8, 2015.

[142] Ehsan Dehghan-Azad, Shady Gadoue and David Atkinson, Sensorless torque-controlled Induction Motor drive for EV applications, IEEE Transportation Electrification Conference and Expo (ITEC), 2017.

[143] Adel Merabet, Aman A. Tanvir and Karim Beddek, Torque and state estimation for real-time implementation of multivariable control in sensorless induction motor drives, IET Electric Power Applications, vol. 11, no. 4, 2017.

[144] Mahmoud A. Mossa and Silverio Bolognani, Effective sensorless Direct Torque Control for an induction motor drive with reduced ripple contents, IEEE International Conference on Power Electronics, Drives and Energy Systems (PEDES), 2016.

[145] Recep Yildiz, Murat Barut and Emrah Zerdali, Load torque and stator resistance estimations with unscented Kalman filter for speed-sensorless control of induction motors, International Conference on Optimization of Electrical and Electronic Equipment (OPTIM) \& 2017 Intl Aegean Conference on Electrical Machines and Power Electronics (ACEMP), 2017.

[146] Siva Ganesh Malla, M. Hema Lata Rao, Jagan Mohana Rao Malla, Rati Ranjan Sabat, Jayadeepu Dadi and Dr. M. Mariya Das, SVM-DTC Permanent Magnet Synchronous Motor Driven Electric Vehicle with Bidirectional Converter, International Multi-Conference on Automation, Computing, Communication, Control and Compressed Sensing (iMac4s), 2013.

[147] Jagan Mohana Rao Malla, Manoj Kumar Sahu, P K Subudhi, DTC-SVM of induction motor by applying two fuzzy logic controllers, International Multi-Conference on Electrical, Electronics, and Optimization Techniques (ICEEOT), 2016. 